\title{
Influence of nutrition on infection and re-infection with soil-transmitted helminths: a systematic review
}

Peiling Yap ${ }^{1,2^{*}}$, Jürg Utzinger ${ }^{1,2}$, Jan Hattendorf ${ }^{1,2}$ and Peter Steinmann $n^{1,2}$

\begin{abstract}
Background: The relationship between nutrition and soil-transmitted helminthiasis is complex and warrants further investigation. We conducted a systematic review examining the influence of nutrition on infection and re-infection with soil-transmitted helminths (i.e. Ascaris lumbricoides, hookworm, Trichuris trichiura and Strongyloides stercoralis) in humans. Emphasis was placed on the use of nutritional supplementation, alongside anthelminthic treatment, to prevent re-infection with soil-transmitted helminths.
\end{abstract}

Methods: We searched eight electronic databases from inception to 31 July 2013, with no restriction of language or type of publication. For studies that met our inclusion criteria, we extracted information on the soil-transmitted helminth species, nutritional supplementation and anthelminthic treatment. Outcomes were presented in forest plots and a summary of findings (SoF) table. An evidence profile (EP) was generated by rating the evidence quality of the identified studies according to the GRADE system.

Results: Fifteen studies met our inclusion criteria; eight randomised controlled trials and seven prospective cohort studies. Data on A. lumbricoides were available from all studies, whereas seven and six studies additionally contained data on T. trichiura and hookworm, respectively. None of the studies contained data on S. stercoralis. Positive effects of nutritional supplementation or the host's natural nutritional status on (re-)infection with soil-transmitted helminths were reported in 14 studies, while negative effects were documented in six studies. In terms of quality, a high, low and very low quality rating was assigned to the evidence from four, six and five studies, respectively.

Conclusions: Our findings suggest that the current evidence-base is weak, precluding guidelines on nutrition management as a potential supplementary tool to preventive chemotherapy targeting soil-transmitted helminthiasis. Moreover, several epidemiological, immunological and methodological issues have been identified, and these should be considered when designing future studies.

Keywords: Soil-transmitted helminths, Nutrition, Anthelminthic treatment, Re-infection, Systematic review

\section{Background}

There is a Chinese proverb that goes "Let food be medicine" (translation of “以食为疗”). The traditional belief that inspired this saying is that, in addition to nutritional value, food has medicinal properties too. Today, it is well established that the consumption of appropriate nutrients is critical to build up one's immune defense against pathogens

\footnotetext{
*Correspondence: p.yap@unibas.ch

${ }^{1}$ Department of Epidemiology and Public Health, Swiss Tropical and Public Health Institute, Basel, Switzerland

¿University of Basel, Basel, Switzerland
}

[1]. Indeed, it has been shown that undernutrition increases the general susceptibility of an individual to viral, bacterial and parasitic infections [2-6], while infections negatively impact on the nutritional status, resulting in a vicious cycle of undernutrition and infection [7-9].

Roundworm (Ascaris lumbricoides), whipworm (Trichuris trichiura), the hookworms (Ancylostoma duodenale and Necator americanus) and threadworm (Strongyloides stercoralis) are collectively termed soil-transmitted helminths [10-12]. Soil-transmitted helminthiases are the most prevalent neglected tropical diseases; over 5 billion people are 
at risk and more than 1 billion people are currently infected $[11,13-16]$. The global burden attributable to these intestinal nematode infections is estimated at 5.2 million disability-adjusted life years (DALYs) [17]. Infections are concentrated in impoverished communities in tropical and sub-tropical regions of sub-Saharan Africa, Asia and Latin America, where poor personal hygiene practices are common and the provision of sanitation and clean water is deficient $[15,16,18-20]$. The World Health Organization (WHO) advocates preventive chemotherapy, the regular administration of anthelminthic drugs to at-risk populations, to control the morbidity due to soil-transmitted helminthiasis [21,22]. However, re-infection occurs rapidly, especially in the absence of targeted hygiene education and measures to improve sanitation and water supply [20,23-25].

In the context of the systematic review presented here, undernutrition is defined as the outcome of insufficient intake, or failure of the body to absorb, one or more essential macro- or micronutrients [3]. According to the Food and Agriculture Organization (FAO) of the United Nations (UN), the global number of undernourished people stood at approximately 870 million in the years 2010 to 2012. The majority of them lived in sub-Saharan Africa, Southern Asia and the Caribbean [26]. Given the geographical overlap with areas where the highest prevalences of soil-transmitted helminth infections are found, it is not surprising that a considerable fraction of undernourished people are simultaneously infected with soil-transmitted helminths. As illustrated in Figure 1, an individual harbouring soil-transmitted helminths might experience anaemia, physiological damage to the gastrointestinal system and other symptoms, which in turn can exacerbate nutritional deficiencies. It is commonly accepted that this could ultimately lead to impaired growth and cognitive development [27-31]. However, findings from studies pertaining to undernutrition and the resulting susceptibility to soil-transmitted helminthiasis are inconclusive, and the true cause-effect relationship, as well as the magnitude of any causal link, remains to be investigated [32].

To address both undernutrition and soil-transmitted helminthiasis, a dual intervention approach has been proposed [5]. Nutritional supplementation is commonly employed to address undernutrition and has been proven to be effective in reducing nutritional deficiencies [33]. However, nutrition management, alongside anthelminthic treatments and with an aim to reduce re-infection with soil-transmitted helminths, remains controversial, and its practical significance and public health potential have yet to be fully explored [32]. Given that one of the Millennium Development Goals (MDGs) is to "halve, between 1990 and 2015, the proportion of people who suffer from hunger" [34], the role of nutrition management on the (re-)infection with soil-transmitted helminths should be investigated. This systematic review summarises the available evidence on influence of nutrition on (re-)infection with soil-transmitted helminths in humans, with a focus on the use of nutritional supplementation, provided together with anthelminthic drugs, to reduce (re-)infection.

\section{Methods}

\section{Criteria for considering studies for this review Types of studies}

We included randomised controlled trials and prospective cohort studies.

\section{Types of outcome measures}

Primary outcomes for single and concurrent infections with soil-transmitted helminths were: (i) (re-)infection rate described as (changes in) prevalence (\%); and (ii)

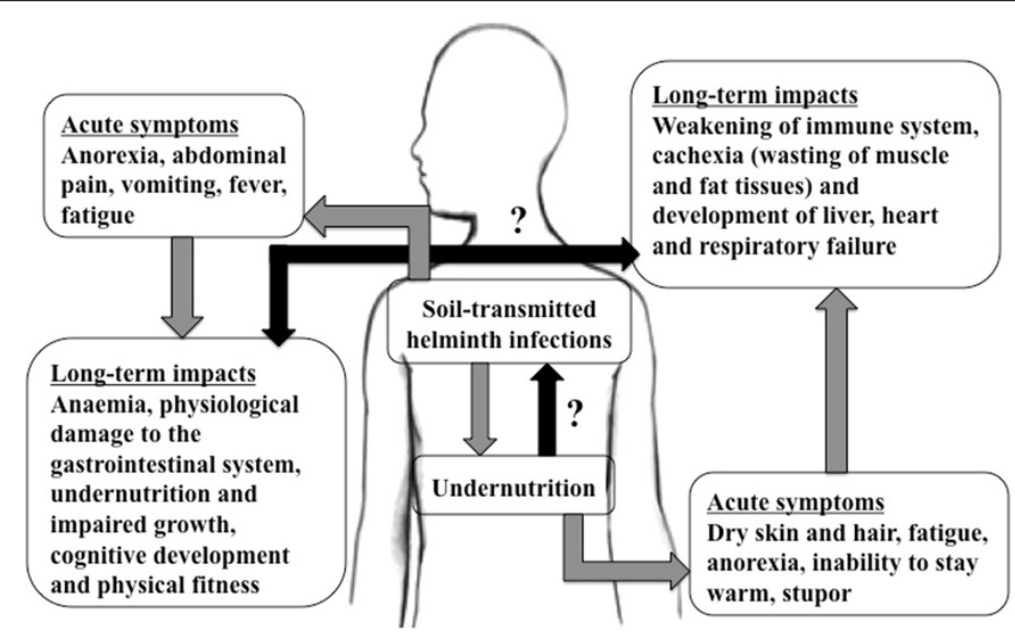

Figure 1 Conceptual framework underpinning this systematic review. The black arrows indicate research gaps in the understanding of the interactions between soil-transmitted helminth infections and undernutrition. 
(changes in) infection intensity in terms of (changes in) eggs per $1 \mathrm{~g}$ of stool (EPG). Secondary outcomes were: (i) immune responses to nutritional supplementation that is relevant for soil-transmitted helminth infections; and (ii) other health benefits of nutritional supplementation. Reported detrimental effects of nutritional supplementation in study participants were recorded as adverse outcomes.

\section{Types of comparisons}

The following comparisons were included in this review: (i) macro-nutrient supplementation versus placebo; (ii) multi-micronutrient supplementation versus placebo; (iii) single micronutrient supplementation versus placebo; and (iv) undernourished hosts versus well-nourished hosts (in their natural states).

\section{Exclusion criteria}

Cross-sectional or case-control studies that compared the nutrition status or growth of infected versus noninfected hosts (in their natural states or treated with anthelminthics) were excluded for their lack of potential to demonstrate causality. Reviews and studies that focused on interactions between malnutrition and immunity in general, with no specific reference to soil-transmitted helminths, were also excluded. Lastly, case reports or case series were also excluded.

\section{Search methods for identification of studies}

We searched eight readily available electronic databases: (i) PubMed/Medline; (ii) Embase; (iii) Cochrane Library; (iv) Cochrane Central Register of Controlled Trials (CENTRAL); (v) Virtual Health Library (VHL); (vi) Science Direct; (vii) China National Knowledge Infrastructure (CNKI); and (viii) VIP Information, from inception to 31 July 2013. No language or publication type restrictions were applied. The following keywords and combinations thereof were used: "reinfection", "soil-transmitted helminths", "multiparasitism", "polyparasitism", "infection intensity", "hookworm”, "Ascaris", "Strongyloides" "Trichuris", "nutrition”, "undernutrition", "malnutrition”, "iron”, "zinc", "vitamin”, "nutrition supplementation" and "micronutrient supplementation". The detailed search strategies are described in Additional file 1: Table S1. Bibliographies of identified studies were checked manually for potential additional references.

\section{Data collection and analysis Selection of studies}

The study selection process was performed by the first author. Potentially relevant studies were identified by screening the titles and, if available, the abstracts of publications. Full manuscript texts were assessed if the relevance of a publication could not be judged from its title or abstract. Finally, the full texts of all potentially relevant studies were evaluated against the predefined inclusion criteria.

\section{Data extraction}

The full text of all selected studies was reviewed and information on the study period, location, design, objectives, method of recruitment, sample size, and sociodemographic characteristics of, and inclusion criteria for, study participants were extracted. In addition, information on the soil-transmitted helminth species and nutritional supplementation used (type, duration, dosage, frequency, type of control group and presence of cointerventions, if any) were gathered, along with both primary and secondary outcomes.

\section{Data analysis}

Where relevant data were available, unadjusted odds ratios (ORs) with 95\% confidence intervals (CIs), comparing prevalence rates among individuals who received nutritional supplementation/were well-nourished, and those who received placebo/were under-nourished, were calculated. Fixed-effects meta-analyses were conducted for A.lumbricoides, T. trichiura, hookworm and, when the results were not species-specific, soil-transmitted helminths combined. No studies were identified for S. stercoralis, precluding any meta-analysis. Unweighted ORs were pooled according to the type of nutritional supplementation/natural nutrition status of the host and an overall OR was also generated. An OR of less than 1.0 indicates a decrease in the odds of being (re-)infected with soil-transmitted helminths among individuals who received nutritional supplementation/were well-nourished. All statistical analyses were performed with STATA version 10.0 (STATA Corp.; College Station, TX, USA).

In addition, qualitative content analysis was conducted for all studies included in the systematic review. Individual outcome measures reported in the articles were summarised and categorised into "strong positive effect", "moderate-to-weak positive effect", and "negative effect". Outcome measures with a $P$-value $<0.05$ were considered to be of statistical significance. The categories were defined as: (i) "strong positive effect" if the intervention/well-nourished group showed a more than two-fold and statistically significant improvement compared to the control/undernourished group; (ii) "moderate-to-weak positive effect" if the improvements were between nil and two-fold or more than two-fold but not statistically significant; and (iii) "negative effect" whenever outcome measures worsened in the intervention/well-nourished group as compared to the control/undernourished group. Consequently, an article could have outcome measures listed in different categories if it contained results of 
different effect size, e.g. for different soil-transmitted helminth species or different interventions.

\section{Quality assessment of included studies}

Following the GRADE rating system [35], outcomes of each study were checked for consistency, precision, directness and the magnitude of the observed effect. The risk of bias was assessed by examining the method of allocation to different study groups; whether randomisation, concealment (protection of the randomisation process to ensure treatment allocation is not known prior to study initiation) or blinding of participants, providers and outcome assessors to the type of intervention received, were performed; the presence of selection, measurement and reporting bias; and loss to follow-up. The evidence quality of the identified studies was rated as high, moderate, low or very low, according to the GRADE guidelines. The full review protocol is available from the corresponding author.

\section{Review}

\section{Characteristics of studies}

The literature searches yielded a total of 13,893 hits (Figure 2). Based on the titles or abstracts, only 20 studies were identified for inclusion. The full texts of all identified studies were retrieved and assessed. Screening of the bibliographies of these studies revealed an additional three studies. Among these 23 studies, eight were excluded (cross-sectional survey, $\mathrm{n}=1$; reviews, $\mathrm{n}=2$; interactions between malnutrition and immunity with no specific reference to soil-transmitted helminths, $\mathrm{n}=2$; small case series of 3-12 individuals, $\mathrm{n}=2$; and unable to obtain the full text, $\mathrm{n}=1$ ) (Additional file 2: Table S2).

Among the 15 studies included in our final analysis, six had been conducted in Central America [36-41]; four in Africa [42-45]; three in Asia [46-48]; and two in South America [49,50]. These studies were all published in English.

Characteristics of the 15 studies are listed in the summary of findings (SoF) table (Table 1 and Additional file 3: Table S3). Eight studies were randomised controlled trials; two of the publications $[47,48]$ actually contained data from the same randomised controlled trial, with different components of the findings published in each of them. In addition, there were seven prospective cohort studies. Data pertaining to A. lumbricoides were available from each study, while seven studies additionally reported data on T. trichiura and six on hookworm. None of the studies identified contained data on S. stercoralis. Fourteen studies included children only, aged between 5 months and 15 years. One study [43] focused on adolescents and adults (age range: 16-63 years). The design of seven studies included the administration of albendazole or mebendazole to participants at baseline and monitoring subjects for re-infection with soil-transmitted helminths over a period of 4 to 15 months, during which regular nutritional supplementation or placebo was provided. Nutritional supplementation included multi-micronutrient

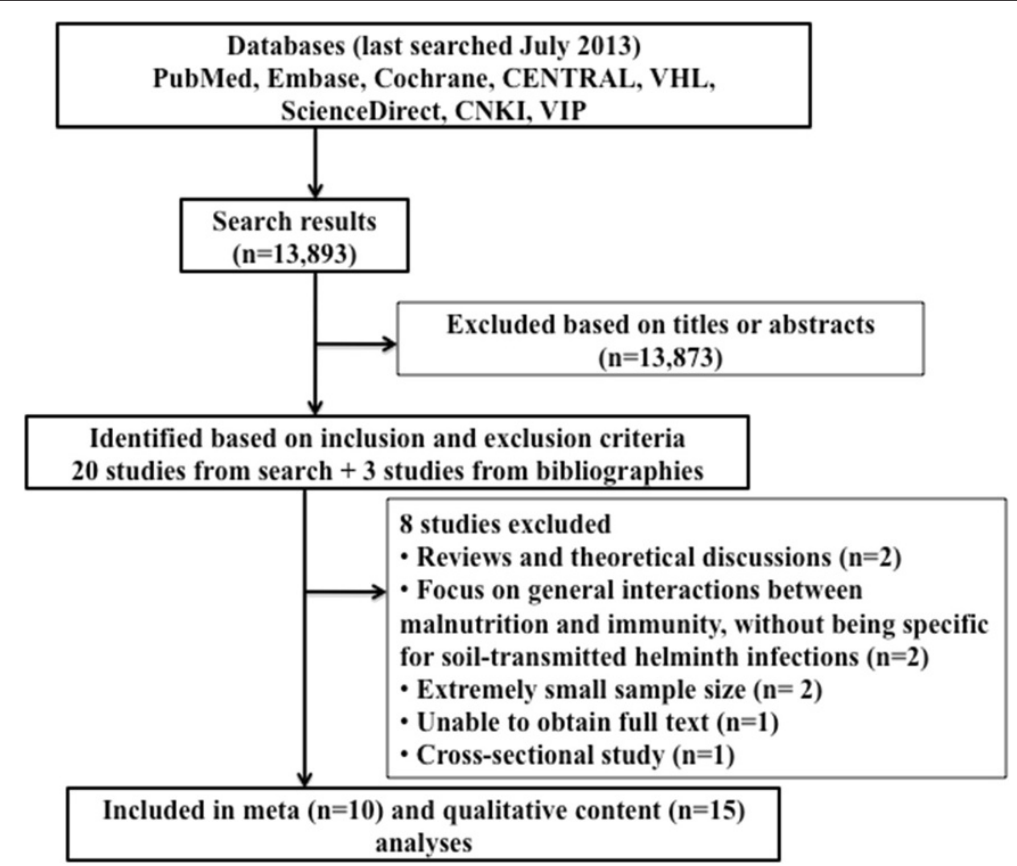

Figure 2 Search strategy for the identification of studies examining the influence of nutrition on (re-)infection with soil-transmitted helminths in humans. 
Table 1 Summary of findings from 15 studies meeting the inclusion criteria of the systematic review pertaining to undernutrition and re-infection with soil-transmitted helminths

\begin{tabular}{|c|c|c|}
\hline & & Characteristics of studies \\
\hline $\begin{array}{l}\text { Study design }{ }^{\mathrm{a}} \text {; } \\
\text { location; sample size; } \\
\text { intestinal helminth } \\
\text { examined }^{\mathrm{b}}\end{array}$ & Study subjects & Intervention/control arms \\
\hline $\begin{array}{l}\text { 1) Nga et al. } 2011 \text { [48]; } \\
\text { factorial RCT; Vietnam; } \\
N=466 ; A, T, H\end{array}$ & 6- to 8-year-old children & $\begin{array}{l}\text { i) Multi-micronutrient biscuits fortified with } \\
\text { iron, zinc, iodine and vitamin A given on } 5 \\
\text { days per week for } 4 \text { months. Albendazole } \\
\text { ( } 400 \text { mg, single dose) at baseline }\end{array}$ \\
\hline
\end{tabular}

ii) Multi-micronutrient biscuits and placebo, identical looking to albendazole

iii) Non-fortified, identical looking biscuits

iv) Non-fortified, identical looking biscuits and albendazole placebo

2) Nga et al. 2009 [47]; 6- to 8-year-old children factorial RCT; Vietnam; $N=466 ; A, T, H$

3) Nchito et al. 2009

[45]; factorial RCT;

Zambia; $\mathrm{N}=215 ; \mathrm{A}$ and albendazole at baseline
7- to 15-year-old children

i) Multi-micronutrient biscuits fortified with iron, zinc, iodine and vitamin A given on 5 days per week for 4 months. Albendazole (400 mg, single dose) at baseline

ii) Multi-micronutrient biscuits and placebo, identical looking to albendazole

iii) Non-fortified, identical looking biscuits and albendazole at baseline

iv) Non-fortified, identical looking biscuits and albendazole placebo

i) Albendazole (400 mg) given to all study participants on 2 consecutive days at baseline
Outcomes

Primary: i) Moderate-to-weak positive effect on the reduction of the infection intensity of all intestinal helminth species in children taking 'fortified biscuits and albendazole' versus 'albendazole alone'

Secondary: Moderate-to-weak positive effect on growth and cognition in children receiving fortified biscuits

Primary: i) Strong positive effect on the reduction of the prevalence of all intestinal helminth species in children taking 'fortified biscuits and albendazole' versus 'albendazole alone'

Secondary: Strong positive effect on reducing anaemia, zinc and iodine deficiencies in children receiving fortified biscuits

Primary: i) Moderate-to-weak effects on the reduction of the prevalence of $A$. lumbricoides in children taking 'iron only' and 'multi-micronutrients only' versus 'placebo'. Negative effect on the reduction of the prevalence of $A$. lumbricoides in children taking 'iron with multi-micronutrients' versus 'placebo'

ii) Multi-micronutrient tablet fortified with vita$\min A, B_{1}, B_{2}, B_{6}, B_{12}, C, D$ and $E$, niacin, folic acid, zinc, iodine, copper and selenium every school day for 10 months. Ferrous dextran tablet (equivalent to $60 \mathrm{mg}$ of elemental iron) every school day for 10 months

iii) Multi-micronutrient tablet and placebo iron tablet

iv) Placebo multi-micronutrient tablet and ferrous dextran tablet

v) Placebo multi-micronutrient tablet and placebo iron tablet

4) Long et al. 2007 [39]; factorial RCT;

Mexico; $\mathrm{N}=707 ; \mathrm{A}$
6- to 15-month-old children

i) Vitamin A (given as 20,000 IU of retinol for children $<1$ year and 45,000 IU for children $>1$ year) every 2 months for 1 year. Zinc methionine (equivalent to $20 \mathrm{mg}$ of elemental zinc)
ii) Zinc methionine only
iii) Vitamin A only
iv) Placebo

ii) Moderate-to-weak positive effect on the reduction of the infection intensity of A. lumbricoides in children taking 'iron only' versus 'placebo'. Negative effects on the reduction of the infection intensity of A. lumbricoides in children taking 'iron with multi-micronutrients' and 'multi-micronutrients only' versus 'placebo'

Primary: i) Strong positive effect on the reduction of the prevalence of $A$. lumbricoides in children taking 'zinc alone' versus 'placebo'. Negative effects on the reduction of the prevalence of $A$. lumbricoides in children taking 'vitamin A with zinc' and 'vitamin A alone' versus placebo

Secondary: i) A combination of vitamin A and zinc had a moderate-to-weak positive effect on the reduction of $A$. lumbricoides infection duration and a strong positive effect on the reduction of $A$. lumbricoides-associated diarrhoea 


\section{Table 1 Summary of findings from 15 studies meeting the inclusion criteria of the systematic review pertaining to undernutrition and re-infection with soil-transmitted helminths (Continued)}

\section{5) Long et al. 2006 [38]; RCT; Mexico;}

$\mathrm{N}=127 ; \mathrm{A}$

6) Olsen et al. 2003

[44]; RCT; Kenya;

$\mathrm{N}=977 ; \mathrm{A}, \mathrm{T}, \mathrm{H}$
5- to 15-month-old children

i) Vitamin A (given as 20,000 IU of retinol for children <1 year and 45,000

IU for children $>1$ year) every 2 months for 15 months

\section{ii) Placebo}

8- to 18-year-old children

i) Albendazole (600 mg, single dose) given to all children at baseline and 4 weeks after baseline (600 mg, single dose) if child was still infected

ii) Multi-micronutrient tablet fortified with vitamin $A, B_{1}, B_{2}, B_{6}, B_{12}, C, D$ and $E$, niacin, folic acid, zinc, iodine, copper, iron and selenium every school day for 11 months

iii) Placebo, identical looking to the

7) Olsen et al. 2000 [43]; RCT; Kenya; $\mathrm{N}=329 ; \mathrm{A}, \mathrm{T}, \mathrm{H}$ ( $n=200)$ and 16- to and adults ( $\mathrm{n}=129$ )

8) Grazioso et al. 1993

65- to 95-month-old

i) Albendazole (400 mg, once a day for 3 consecutive days) at baseline for all individuals and if any individual was still infected between 3 and 6 months after baseline, re-treatment $(400 \mathrm{mg}$, single dose) was given

ii) Ferrous dextran tablet (equivalent to $60 \mathrm{mg}$ of elemental iron) twice weekly for 12 months

iii) Placebo identical looking to the ferrous dextran tablet

i) Mebendazole (100 mg twice daily for 3 days) at baseline for all individuals
4- to 15-year-old children 63-year-old adolescents [36]; RCT; Guatemala; $\mathrm{N}=130 ; \mathrm{A}, \mathrm{T}$

children

9) Halpenny et al. $2013<5$-year-old children [41]; CP; Panama; $\mathrm{N}=87-279 ; \mathrm{A}, \mathrm{H}$ ii) Tablet containing zinc (10 mg) and vitamin $A, E, C, B_{6}, B_{12}$ and $D$, folic acid, thiamin, riboflavin, niacinamide, pantothenic acid, iron, copper, iodine, selenium, chromium and magnesium given on every school day for 120-150 days

iii) Different colour-coded tablets, containing all the micronutrients, except for zinc, found in the intervention tablet

i) Cycle 1: albendazole (200-400 mg depending on age, single dose) to all children >12 months at baseline. Children followed up for 9 months

ii) Cycle 2: albendazole (200-400 mg depending on age, single dose) to all children > 12 months at baseline. Children who remained infected with at least 1 soil-transmitted helminth were given another single dose of albendazole. Children followed up for 6 months

10) Hesham Al-Mekhlafi 7- to 12-year-old children et al. 2008 [46];

CP; Malaysia;

$\mathrm{N}=120 ; \mathrm{A}, \mathrm{T}, \mathrm{H}$

i) Albendazole (400 mg, once a day for 3 consecutive days) for all children at baseline. Children followed for 6 months to investigate predictors of re-infection multi-micronutrient tablet

Secondary: i) Strong positive effect on the increase of interleukin 4 (IL-4) levels in vitamin A supplemented children versus placebo

Primary: i) For children taking 'multi-micronutrients' versus 'placebo', moderate-to-weak positive effects on the reduction of the prevalence of A. lumbricoides and hookworm and negative effect on the reduction of the prevalence of $T$. trichiura

ii) For children taking 'multi-micronutrients' versus 'placebo', moderate-to-weak positive effects on the reduction of the infection intensity of all intestinal helminth species

Primary: i) For children taking 'iron' versus 'placebo', moderate-to-weak positive effects on the reduction of the prevalence of all intestinal helminth species and in the reduction of infection intensity of hookworm. Negative effects on the reduction of infection intensity of A. lumbricoides and T. trichiura

ii) For adolescents/adults taking 'iron' versus 'placebo', strong positive effects on the reduction of the prevalence of $A$. lumbricoides and T. trichiura and moderate-to-weak positive effect on the reduction of the prevalence of hookworm. In terms of infection intensity reduction, negative effects for $A$. lumbricoides and $T$. trichiura and moderate-to-weak positive effect for hookworm

Primary: i) Negative effect on the reduction of the prevalence of A. lumbricoides and T. trichiura (mentioned collectively) in children taking 'zinc' versus 'placebo'

Primary: i) Strong positive effect on the reduction of $A$. lumbricoides infection intensity at the end of cycle 1 in children with higher height-for-age (HAZ) versus their peers with lower HAZ scoreii) Strong positive effect on the reduction of hookworm infection intensity at the end of cycle 2 in children with higher height-for-age (HAZ) versus their peers with lower HAZ score
Primary: i) Moderate-to-positive effects on the reduction of the prevalence of $A$. lumbricoides, T. trichiura and hookworm (mentioned collectively) in non-stunted children versus stunted children 


\section{Table 1 Summary of findings from 15 studies meeting the inclusion criteria of the systematic review pertaining to undernutrition and re-infection with soil-transmitted helminths (Continued)}

11) Payne et al. $2007 \quad$ 12- to 60 -month-old children
[40]; CP; Panama;
$N=328 ; A$

12) Saldiva et al. $2002 \quad$ 1- to 10-year-old children
[37]; CP; Brazil;
$N=585 ;$ A, T

$\mathrm{N}=585 ; \mathrm{A}, \mathrm{T}$

\section{i) One-off supplementation with vitamin A (60 $\mathrm{mg}$ retinol) given by the Ministry of Health}

ii) Albendazole (400 mg, single dose) for a children at baseline. Children were followed at 3 and 5 months posttreatment

i) Mebendazole (triple doses at baseline and repeated 15 days after). Children were followed at 1 year post-treatment

i) Oxantel/pyrantel $(20 \mathrm{mg} / \mathrm{kg})$ monthly for 12 months for all children. Children were followed at 8 months after the 12 months of treatment

14) Kightlinger et al. 4- to 10-year-old children
1996 [42]; CP;
Madagascar;
$N=360-619 ; A$

15) Hagel et al. 1995 [49]; CP; Venezuela; 6- to 11-year-old children $\mathrm{N}=85 ; \mathrm{A}$ given to all children at baseline. Children were followed at the end of 12 months, when they were given pyrantel pamoate (11 mg/kg) and 48-hour worm expulsions were performed

i) Oxantel/pyrantel $(20 \mathrm{mg} / \mathrm{kg})$ monthly for 12 months for all children. Children were followed at the end of the 12 months of treatment i) Mebendazole (500 mg, single dose) was
Primary: i) Moderate-to-weak positive effect on the reduction of the $A$. lumbricoides prevalence and infection intensity in vitamin A-supplemented children versus non-supplemented ones

Primary: i) Moderate-to-weak positive effect on the reduction of the prevalence of A. lumbricoides and T. trichiura (mentioned collectively with other helminths, such as Hymenolepsis nana and S. stercoralis) in eutrophic children versus undernourished children

Primary: i) Strong positive effect on the reduction of the prevalence of A. lumbricoides in children $>10$ th percentile for height versus children $\leq 10$ th percentile for height

Primary: i) Moderate-to-weak positive effect on the reduction of the infection intensity of A. lumbricoides in the best-nourished children versus children with reduced growth indicators

Secondary: i) Strong positive effect on an increase of anti-Ascaris lgE levels in well-nourished children versus under-nourished children

${ }^{\mathrm{a}} \mathrm{CP}$, cohort prospective; $\mathrm{RCT}$, randomised controlled trial.

${ }^{\mathrm{b}} \mathrm{A}$, A. lumbricoides; $\mathrm{H}$, hookworm; $\mathrm{T}, \mathrm{T}$. trichiura.

biscuits or tablets, vitamin A given as retinol solution, zinc administered as zinc methionine solution or iron taken as ferrous dextran tablets. In two studies [38,39], young children, aged 5-15 months, were given only nutritional supplementation or placebo, without preventive chemotherapy, and followed for 12-15 months for A. lumbricoides infection or immune responses against this nematode. Finally, six studies evaluated albendazole, mebendazole or oxantel/ pyrantel treatments with evaluation of the participants, stratified by their natural nutrition states, occurring 8 months [50] or 12 months [49] after the treatment period. In another study, albendazole was administered to children who were followed, in their natural nutrition states, over two treatment and re-infection cycles [41].

\section{Quality of evidence in included studies}

Among the 15 studies included in this review, only four contained evidence graded as high quality (i.e. no serious limitation, inconsistency, indirectness and imprecision were present and no risk of bias was detected). No study had evidence of moderate quality. Evidence in six studies was given a low quality rating and evidence from another five studies was determined to be of very low quality (Table 2). When stratified according to the impact of the outcome measures, the eight studies with strong positive impact contained three (27\%) high, four (45\%) low and one (27\%) very low quality evidence; the nine studies with moderate-to-weak positive effect were made up of two (22\%) high, four (44\%) low and three (33\%) very low quality pieces of evidence; and the six studies with negative effect included one (17\%) high, four $(67 \%)$ low and one (17\%) very low quality evidence items.

\section{Influence of nutrition on soil-transmitted helminth infections Multi-micronutrients}

Multi-micronutrients, taken in the form of biscuits or tablets, lowered the re-infection rate with $A$. lumbricoides (OR: 0.76, 95\% CI: 0.59-0.98, Figure 3A) and T. trichiura (OR: 0.76, 95\% CI: 0.55-1.06, Figure 3B) but the decline failed to reach statistical significance $[44,45,47]$; the quality of this evidence is moderate. Slightly higher re-infection rates were observed for hookworm in subjects given micronutrients, again without statistical significance (OR: 1.08, 95\% CI: 0.61-1.92, Figure 3C). The quality of this evidence is moderate. Regarding re-infection intensity, two studies containing moderate quality evidence reporting moderate-to-weak positive effects were identified for all three intestinal helminth species (1,443 participants) $[44,48]$, and one study of low quality evidence reporting negative effects was identified for A. lumbricoides (215 participants) [45]. In terms of secondary outcome 
Table 2 GRADE evidence profile (EP) for the 15 studies included in the systematic review

\begin{tabular}{|c|c|c|c|c|c|c|}
\hline \multirow[b]{2}{*}{ Study } & \multicolumn{6}{|l|}{ Quality assessment of evidence } \\
\hline & Limitation & Inconsistency & Indirectness & Imprecision & Risk of bias & Quality grading \\
\hline 1) Nga et al. 2011 [48] & No serious limitation & No serious inconsistency & $\begin{array}{l}\text { No serious } \\
\text { indirectness }\end{array}$ & No serious imprecision & None detected & $\oplus \oplus \oplus \oplus \mathrm{High}$ \\
\hline 2) Nga et al. 2009 [47] & No serious limitation & No serious inconsistency & $\begin{array}{l}\text { No serious } \\
\text { indirectness }\end{array}$ & No serious imprecision & None detected & $\oplus \oplus \oplus \oplus \mathrm{High}$ \\
\hline 3) Nchito et al. 2009 [45] & $\begin{array}{l}\text { Serious limitation (sample size } \\
\text { used for analysis was smaller than } \\
\text { that required for statistical } \\
\text { significance; mean number of } \\
\text { supplementation tablets taken } \\
\text { was only } 50 \% \text { of tablets provided) }\end{array}$ & $\begin{array}{l}\text { Serious inconsistency } \\
\text { (administration of albendazole } \\
\text { at baseline was not stated } \\
\text { under study design but was } \\
\text { mentioned under results) }\end{array}$ & $\begin{array}{l}\text { No serious } \\
\text { indirectness }\end{array}$ & No serious imprecision & $\begin{array}{l}\text { Serious risk of bias ( } 47 \% \text { of } \\
\text { children were lost to follow-up; } \\
\text { method of recruitment and } \\
\text { inclusion/exclusion criteria were } \\
\text { not mentioned) }\end{array}$ & $\oplus \oplus \bigcirc \bigcirc$ Low \\
\hline 4) Long et al. 2007 [39] & No serious limitation & No serious inconsistency & $\begin{array}{l}\text { No serious } \\
\text { indirectness }\end{array}$ & No serious imprecision & None detected & $\oplus \oplus \oplus \oplus$ High \\
\hline 5) Long et al. 2006 [38] & No serious limitation & No serious inconsistency & $\begin{array}{l}\text { No serious } \\
\text { indirectness }\end{array}$ & No serious imprecision & None detected & $\oplus \oplus \oplus \oplus$ High \\
\hline 6) Olsen et al. 2003 [44] & $\begin{array}{l}\text { Serious limitation (compliance } \\
\text { rates for the multi-micronutrient } \\
\text { tablet and placebo were low at } \\
46 \%)\end{array}$ & $\begin{array}{l}\text { Serious inconsistency (the } \\
\text { allocation of anthelminthic } \\
\text { treatment and placebo was } \\
\text { not clear) }\end{array}$ & $\begin{array}{l}\text { No serious } \\
\text { indirectness }\end{array}$ & No serious imprecision & $\begin{array}{l}\text { Serious risk of bias (number of } \\
\text { stool samples collected for } \\
\text { each child varied) }\end{array}$ & $\oplus \oplus \bigcirc \bigcirc$ Low \\
\hline 7) Olsen et al. 2000 [43] & No serious limitation & $\begin{array}{l}\text { Serious inconsistency } \\
\text { (reporting of results was not } \\
\text { consistent for all helminth } \\
\text { species) }\end{array}$ & $\begin{array}{l}\text { No serious } \\
\text { indirectness }\end{array}$ & No serious imprecision & $\begin{array}{l}\text { Serious risk of bias (method of } \\
\text { recruitment and blinding } \\
\text { procedures not mentioned; } \\
\text { number of stool samples } \\
\text { collected varied at each } \\
\text { follow-up) }\end{array}$ & $\oplus \oplus \bigcirc \bigcirc$ Low \\
\hline 8) Grazioso et al. 1993 [36] & No serious limitation & $\begin{array}{l}\text { Serious inconsistency (data } \\
\text { reported under abstract is } \\
\text { different from that found in } \\
\text { the results section) }\end{array}$ & $\begin{array}{l}\text { No serious } \\
\text { indirectness }\end{array}$ & $\begin{array}{l}\text { Serious imprecision } \\
\text { (stratification of results } \\
\text { according to soil-transmitted } \\
\text { helminth species was not } \\
\text { performed) }\end{array}$ & $\begin{array}{l}\text { Very serious risk of bias } \\
\text { (number of intervention days } \\
\text { not clear; reporting of primary } \\
\text { outcome measures were not } \\
\text { complete) }\end{array}$ & $\oplus \bigcirc \bigcirc \bigcirc$ Very low \\
\hline 9) Halpenny et al. 2013 [41] & $\begin{array}{l}\text { Serious limitation (compliance } \\
\text { rate for albendazole at both } \\
\text { treatment cycles was low at 48\%) }\end{array}$ & No serious inconsistency & $\begin{array}{l}\text { No serious } \\
\text { indirectness }\end{array}$ & No serious imprecision & None detected & $\oplus \oplus \bigcirc \bigcirc$ Low \\
\hline $\begin{array}{l}\text { 10) Hesham Al-Mekhlafi } \\
\text { et al. } 2008 \text { [46] }\end{array}$ & No serious limitation & $\begin{array}{l}\text { Serious inconsistency } \\
\text { (reporting of sample size was } \\
\text { not consistent throughout the } \\
\text { study) }\end{array}$ & $\begin{array}{l}\text { No serious } \\
\text { indirectness }\end{array}$ & $\begin{array}{l}\text { Serious imprecision } \\
\text { (stratification of results } \\
\text { according to soil-transmitted } \\
\text { helminth species was not } \\
\text { performed) }\end{array}$ & None detected & $\oplus \bigcirc \bigcirc \bigcirc$ Very low \\
\hline 11) Payne et al. 2007 [40] & No serious limitation & No serious inconsistency & $\begin{array}{l}\text { No serious } \\
\text { indirectness }\end{array}$ & No serious imprecision & $\begin{array}{l}\text { Serious risk of bias (vitamin A } \\
\text { supplemented children came } \\
\text { from families with significantly } \\
\text { higher income and latrine access } \\
\text { than the non-supplemented }\end{array}$ & $\oplus \oplus \bigcirc \bigcirc$ Low \\
\hline
\end{tabular}
than the non-supplemented 
Table 2 GRADE evidence profile (EP) for the 15 studies included in the systematic review (Continued)

\begin{tabular}{|c|c|c|c|c|c|c|}
\hline & & & & & $\begin{array}{l}\text { children; } 34 \% \text { children were lost } \\
\text { to follow-up) }\end{array}$ & \\
\hline 12) Saldiva et al. 2002 [37] & No serious limitation & $\begin{array}{l}\text { Serious inconsistency } \\
\text { (stratification of undernourished } \\
\text { and eutrophic children not clear) }\end{array}$ & $\begin{array}{l}\text { No serious } \\
\text { indirectness }\end{array}$ & $\begin{array}{l}\text { Serious imprecision } \\
\text { (stratification of results } \\
\text { according to soil-transmitted } \\
\text { helminth species was not } \\
\text { performed) }\end{array}$ & None detected & $\oplus \bigcirc \bigcirc \bigcirc$ Very low \\
\hline 13) Hagel et al. 1999 [50] & No serious limitation & No serious inconsistency & $\begin{array}{l}\text { No serious } \\
\text { indirectness }\end{array}$ & No serious imprecision & $\begin{array}{l}\text { Serious risk of bias (poverty level } \\
\text { as a confounding factor was not } \\
\text { taken into account during data } \\
\text { analysis) }\end{array}$ & $\oplus \bigcirc \bigcirc \bigcirc$ Very low \\
\hline $\begin{array}{l}\text { 14) Kightlinger et al. } \\
\text { 1996 [42] }\end{array}$ & No serious limitation & $\begin{array}{l}\text { Serious inconsistency (number } \\
\text { of children included for } \\
\text { analysis varied for different } \\
\text { outcome measures) }\end{array}$ & $\begin{array}{l}\text { No serious } \\
\text { indirectness }\end{array}$ & No serious imprecision & $\begin{array}{l}\text { Serious risk of bias (about } 41 \% \\
\text { children were lost to follow-up) }\end{array}$ & $\oplus \bigcirc \bigcirc \bigcirc$ Very low \\
\hline 15) Hagel et al. 1995 [49] & No serious limitation & No serious inconsistency & $\begin{array}{l}\text { No serious } \\
\text { indirectness }\end{array}$ & No serious imprecision & None detected & $\oplus \oplus \bigcirc \bigcirc$ Low \\
\hline
\end{tabular}




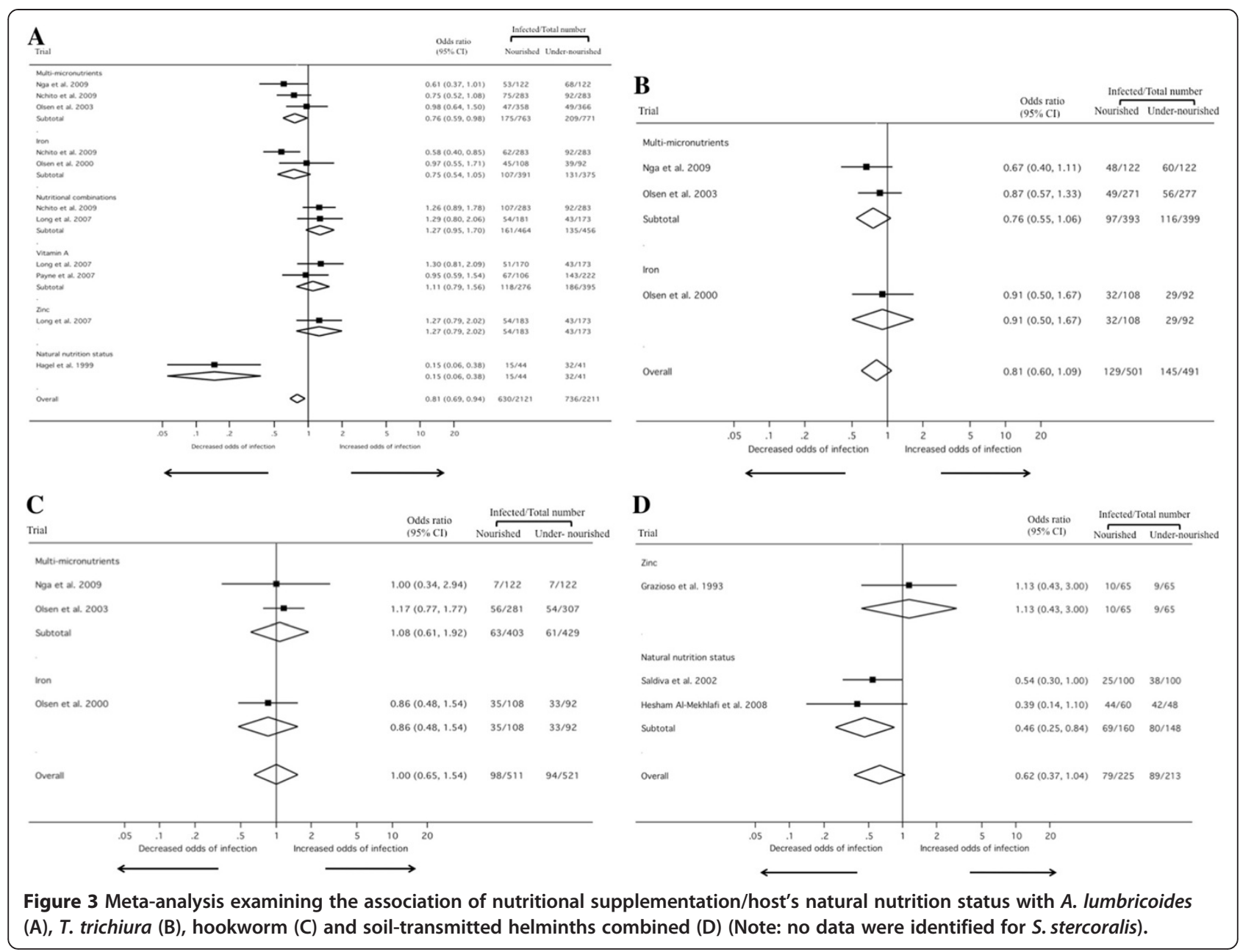

measures, multi-micronutrients had a strong positive effect on reducing the odds of anaemia, zinc and iodine deficiencies, but only a moderate-to-weak positive effect on growth and cognition in one study (466 participants, high quality evidence) $[47,48]$.

\section{Iron}

Iron tablets probably decrease the re-infection rate with A. lumbricoides (OR: 0.75, 95\% CI: 0.54-1.05, Figure 3A), but the quality of this evidence is low $[43,45]$. Iron might also reduce the $A$. lumbricoides infection intensity (two studies reporting moderate-to-weak positive effects, 544 participants, low quality evidence) $[43,45]$. It is not clear what effect iron has on the re-infection rate and infection intensity with $T$. trichiura and hookworm, as only one study with moderate-to-weak and negative effects (329 participants, low quality evidence) was identified [43].

\section{Vitamin A}

Vitamin A supplementation showed no effect on reinfection with $A$. lumbricoides (OR: 1.11, 95\% CI: 0.79-1.56,
Figure 3A; quality of evidence is moderate) [39,40]. With regards to a reduction of $A$. lumbricoides infection intensity, only one low-quality evidence with moderateto-weak positive effects was found (328 participants) [40]. We identified no studies examining the impact of vitamin A on T. trichiura and hookworm re-infection. In terms of secondary outcome measures, vitamin A increased the odds of having improved levels of IL-4, which is part of the Th2 response against helminths, in one study (strong positive effect, 127 participants, high quality evidence) [38].

\section{Zinc}

Zinc might have a negative effect on the $A$. lumbricoides re-infection rate as one study (707 participants, high quality evidence) [39] showed an increase in the prevalence of this parasite in children who took zinc tablets and another study (130 participants, very low quality evidence) [36] also found that zinc-supplemented children fared worse than their placebo counterparts in terms of soiltransmitted helminth re-infection (A. lumbricoides and $T$. trichiura were treated collectively and no stratification of 
results is available in the published article; Figure 3D). No other studies investigating the impact of zinc on T. trichiura and hookworm re-infection were identified.

\section{Nutritional combinations}

Nutritional combination therapies might slightly increase the $A$. lumbricoides re-infection rate. We identified two studies, one combining iron and multi-micronutrients (OR: 1.26, 95\% CI: 0.89-1.78, Figure 3A) [45], and the second, vitamin A plus zinc (OR: 1.29, 95\% CI: 0.802.06, Figure 3A) [39]. In terms of secondary outcomes, another study reported that a combination of zinc and vitamin A reduced the mean duration of A. lumbricoides infections (moderate-to-weak positive effect) and lowered the incidence of A.lumbricoides-associated diarrhoea (strong positive effect; 707 participants, high quality evidence) [39].

\section{Natural nutrition status of the host}

The natural nutrition status of the host might have an impact on soil-transmitted helminth re-infection according to one low-quality evidence which showed strong positive effects (279 participants; Figure 3D) [37,41,46], and four very low-quality evidences (one with strong positive and three with moderate-to-weak positive effects, 1,409 participants) [42,50]. Indeed, these five studies found that children considered to be well nourished had lower soil-transmitted helminth re-infection rates and intensities compared to their under-nourished peers. In terms of secondary outcome measures, hosts with a better nutrition status were found to have higher levels of anti-Ascaris IgE levels (strong positive effect) than those with poor nutrition indicators in one study (85 participants, low quality evidence) [49].

\section{Discussion}

There is a considerable body of literature on the effects of macro- and micronutrients on host immune function and their association with infectious diseases [2,5,6,8,32,51]. However, little is known whether nutritional deficiencies have an effect on the susceptibility to infection and reinfection with soil-transmitted helminths. To fill this gap, we conducted a systematic review examining the influence of nutrition on infection and re-infection with soiltransmitted helminths. We focused particularly on the use of nutritional supplementation to prevent re-infection following anthelminthic treatment. The results from our systematic review indicate that, first, only few studies are available and, second, most of the evidence on the effects of nutritional supplementation and undernutrition on (re-)infection with soil-transmitted helminths is of low quality. Among the various nutritional supplementation interventions reviewed, multi-micronutrient supplementation seemed to have the clearest effect in terms of lowering re-infection rates and intensity of soil-transmitted helminths, whereas consumption of zinc or vitamin A alone might have a negative effect on these two outcome measures. With regard to the natural nutrition status of the host, the general trend observed was that individuals with poor nutrition indicators experienced higher re-infection rates and intensities than their well-nourished counterparts. However, the risk of confounding is higher in studies focusing on the natural nutrition status rather than controlled supplementation following randomisation. Hence, findings from the former studies have to be interpreted with care.

The evidence reported here must be seen in conjunction with the strengths and limitations of our systematic review. In terms of strength, we conducted a broad search including eight major electronic scientific literature databases that were systematically reviewed for relevant articles, complemented with hand-searches of bibliographies of identified articles. The reporting of the review was done based on the PRISMA guidelines (Additional file 4: Table S4) [52], while the GRADE system [35] was adopted for grading the quality of the reported evidence. A combination of meta-analysis and qualitative content analysis was adopted to ensure a comprehensive review. Due to the small number of studies identified, most of which with low quality evidence that is statistically insignificant, the unweighted pooled ORs should be interpreted with caution. Therefore, it is also statistically irrelevant to detect heterogeneity with Moran's $I^{2}$ or publication bias with the Egger's test. However, a potential publication bias was noted based on the forest plots, where studies with smaller sample sizes presented more significant results than studies with larger sample sizes. Finally, no "grey literature" and experts' opinions were included as the quality and strength of evidence of these sources is usually lower than that of articles published in the peer-reviewed literature.

There are several shortcomings in the included studies. None of the studies investigated the effect of nutritious whole foods as an intervention. Nutrients delivered by whole foods derived from the biological environment of the study population might have a distinct impact compared to synthetic supplements, since consumption of a broad range of nutrients from their natural sources might aid in their absorption and assimilation into the body [53]. Earlier work [54,55] did attempt to improve on whole diets and assess their impact on hookworm infection but the ill-controlled dietary changes render it difficult to appreciate these results. The more recent use of multi-micronutrient-fortified biscuits by Nga and coworkers $[47,48]$ is a compromise between the two ends of the spectrum, allowing artificial nutrients to be delivered through food. However, this is the only group that employed this strategy and more evidence is needed to confirm its efficacy in preventing re-infection with soiltransmitted helminths. 
It must be noted that nutrients often have interactions that affect their absorption and presumably their impact on soil-transmitted helminth (re-)infection. Antagonistic interactions were observed in two studies pertaining to A. lumbricoides infection $[39,45]$. However, in one of these studies [39], vitamin A and zinc were also shown to work synergistically and better than placebo or taking the supplements individually in reducing the mean duration of $A$. lumbricoides infection and the incidence of diarrhoea. In order to fully exploit the potential of nutritional supplementation for reducing (re-)infection with soil-transmitted helminths, the careful identification of synergistic combinations of supplements is thus required.

On a more fundamental note, it is currently unclear how long it will take for a reliable source of nutrition to become utilised for the building up of immune defenses and not for catching up on retarded growth. Many of the populations from the studies reviewed here have suffered from chronic undernutrition and high prevalence of soil-transmitted helminths and other infectious diseases, and hence, the treatment, nutritional supplementation given and the observation period might not be adequate or sufficient for the body to recover from the accumulated growth retardation, to wipe out infections and to strengthen the immune system at the same time. Therefore, more rigorous chemotherapies, such as triple-dose regimens or combination therapies [56-60] repeated over an extended period of time as well as continuous nutritional supplementation or markedly improved food supplies both in terms of quality and quantity might be needed. Such a situation might be more suitable for an accurate test of the impact of nutritional supplementation on (re-) infection with soil-transmitted helminths.

\section{Conclusions}

We conclude that the current evidence-base for the effect of nutrition on (re-)infection with soil-transmitted helminths is weak and of low quality. Hence, no guidelines on nutrition management with or without preventive chemotherapy can be derived from it. In order to generate the required evidence for policy makers to base their recommendations on, future studies should focus on having a rigorous study design, and consider whole foods, the entire diet as well as combination supplementation as intervention tools. Making sure that the body has sufficient time to recover from undernutrition and soil-transmitted helminth infection before the final evaluation of the intervention is another requirement. Finally, it is important to realise that multi-pronged approaches are probably necessary to prevent and control the negative effects of soiltransmitted helminth infections, including anthelminthic drugs, safe water and sanitation, proper hygiene habits and, possibly, improved nutrition.

\section{Additional files}

Additional file 1: Table S1. Detailed search strategies for this systematic review.

Additional file 2: Table S2. List of the eight studies excluded from this systematic review.

Additional file 3: Table S3. Detailed summary of primary and secondary outcomes of the 15 studies retained for inclusion in the systematic review.

Additional file 4: Table S4. PRISMA checklist.

\section{Competing interests}

The authors declare that they have no competing interests.

\section{Authors' contributions}

PY conceived the study, extracted, analysed and interpreted the data and prepared the manuscript. $J U$ and $J H$ interpreted the data and revised the manuscript. PS conceived the study, interpreted the data and revised the manuscript. All authors read and approved the final version of the manuscript.

\section{Acknowledgements}

We are grateful to the librarians from the Swiss Tropical and Public Health Institute for their assistance in obtaining requested articles.

Received: 2 January 2014 Accepted: 6 May 2014

Published: 19 May 2014

\section{References}

1. Kau AL, Ahern PP, Griffin NW, Goodman AL, Gordon Jl: Human nutrition, the gut microbiome and the immune system. Nature 2011, 474:327-336.

2. Carr AC, Frei B: Toward a new recommended dietary allowance for vitamin $C$ based on antioxidant and health effects in humans. Am J Clin Nutr 1999, 69:1086-1107.

3. Gershwin ME, German JB, Keen CL: Nutrition and Immunology: Principles and Practice. New York: Humana Press; 2000.

4. Ing R, Su Z, Scott ME, Koski KG: Suppressed T helper 2 immunity and prolonged survival of a nematode parasite in protein-malnourished mice. Proc Natl Acad Sci U S A 2000, 97:7078-7083.

5. Katona $P$, Katona-Apte J: The interaction between nutrition and infection. Clin Infect Dis 2008, 46:1582-1588.

6. Maggini S, Wenzlaff S, Hornig D: Essential role of vitamin C and zinc in child immunity and health. J Int Med Res 2010, 38:386-414.

7. Scrimshaw NS, Taylor CE, Gordon JE: Interactions of nutrition and infection. Am J Med Sci 1959, 237:367-403.

8. Scrimshaw NS, SanGiovanni JP: Synergism of nutrition, infection, and immunity: an overview. Am J Clin Nutr 1997, 66:464S-477S.

9. Keusch GT: The history of nutrition: malnutrition, infection and immunity. J Nutr 2003, 133:336S-340S.

10. Cox FEG: History of human parasitology. Clin Microbiol Rev 2002, 15:595-612.

11. Bethony J, Brooker S, Albonico M, Geiger SM, Loukas A, Diemert D, Hotez PJ: Soil-transmitted helminth infections: ascariasis, trichuriasis, and hookworm. Lancet 2006, 367:1521-1532.

12. Knopp S, Steinmann P, Keiser J, Utzinger J: Nematode infections: soil-transmitted helminths and Trichinella. Infect Dis Clin North Am 2012, 26:341-358.

13. Hotez PJ, Molyneux DH, Fenwick A, Kumaresan J, Sachs SE, Sachs JD, Savioli L: Control of neglected tropical diseases. N Engl J Med 2007, 357:1018-1027.

14. Brooker S: Estimating the global distribution and disease burden of intestinal nematode infections: adding up the numbers - a review. Int J Parasitol 2010, 40:1137-1144.

15. Pullan RL, Brooker SJ: The global limits and population at risk of soil-transmitted helminth infections in 2010. Parasit Vectors 2012, $5: 81$. 
16. Pullan RL, Smith JL, Jasrasaria R, Brooker SJ: Global numbers of infection and disease burden of soil transmitted helminth infections in 2010. Parasit Vectors 2014, 7:37

17. Murray CJL, Vos T, Lozano R, Naghavi M, Flaxman AD, Michaud C, Ezzati M, Shibuya K, Salomon JA, Abdalla S, Aboyans V, Abraham J, Ackerman I, Aggarwal R, Ahn SY, Ali MK, Alvarado M, Anderson HR, Anderson LM, Andrews KG, Atkinson C, Baddour LM, Bahalim AN, Barker-Collo S, Barrero LH, Bartels DH, Basáñez MG, Baxter A, Bell ML, Benjamin EJ, et al: Disability-adjusted life years (DALYs) for 291 diseases and injuries in 21 regions, 1990-2010: a systematic analysis for the Global Burden of Disease Study 2010. Lancet 2012, 380:2197-2223

18. Brooker S, Clements ACA, Bundy DAP: Global epidemiology, ecology and control of soil-transmitted helminth infections. Adv Parasitol 2006, 62:221-261

19. Chammartin F, Scholte RGC, Guimarães LH, Tanner M, Utzinger J, Vounatsou P: Soil-transmitted helminth infection in South America: a systematic review and geostatistical meta-analysis. Lancet Infect Dis 2013, 13:507-518

20. Strunz EC, Addiss DG, Stocks ME, Ogden S, Utzinger J, Freeman MC: Water, sanitation, hygiene, and soil-transmitted helminth infection: a systematic review and meta-analysis. PLoS Med 2014, 11:e1001620.

21. Utzinger J, Keiser J: Schistosomiasis and soil-transmitted helminthiasis: common drugs for treatment and control. Expert Opin Pharmacother 2004, 5:263-285.

22. WHO: Eliminating soil-transmitted helminthiasis as a public health problem in children. Geneva: World Health Organization; 2012.

23. Hall A: Micronutrient supplements for children after deworming. Lancet Infect Dis 2007, 7:297-302.

24. Jia TW, Melville S, Utzinger J, King CH, Zhou XN: Soil-transmitted helminth reinfection after drug treatment: a systematic review and meta-analysis. PLoS Negl Trop Dis 2012, 6:e1621.

25. Ziegelbauer K, Speich B, Mäusezahl D, Bos R, Keiser J, Utzinger J: Effect of sanitation on soil-transmitted helminth infection: systematic review and meta-analysis. PLoS Med 2012, 9:e1001162.

26. FAO: Undernourishment Around the World in 2012. Rome: Food and Agriculture Organization of the United Nations; 2012.

27. Stephenson LS, Latham MC, Ottesen EA: Malnutrition and parasitic helminth infections. Parasitology 2000, 121(Suppl):S23-S38.

28. Crompton DWT, Nesheim MC: Nutritional impact of intestinal helminthiasis during the human life cycle. Annu Rev Nutr 2002, 22:35-59.

29. Zhou H, Watanabe C, Ohtsuka R: Impacts of dietary intake and helminth infection on diversity in growth among schoolchildren in rural south China: a four-year longitudinal study. Am J Hum Biol 2007 19:96-106.

30. Mupfasoni D, Karibushi B, Koukounari A, Ruberanziza E, Kaberuka T, Kramer MH, Mukabayire O, Kabera M, Nizeyimana V, Deville MA, Ruxin J, Webster JP, Fenwick A: Polyparasite helminth infections and their association to anaemia and undernutrition in Northern Rwanda. PLoS Negl Trop Dis 2009, 3:e517.

31. Hall A, Zhang Y, Macarthur C, Baker S: The role of nutrition in integrated programs to control neglected tropical diseases. BMC Med 2012, 10:41.

32. Koski KG, Scott ME: Gastrointestinal nematodes, nutrition and immunity: breaking the negative spiral. Annu Rev Nutr 2001, 21:297-321.

33. Stratton RJ, Elia M: Encouraging appropriate, evidence-based use of oral nutritional supplements. Proc Nutr Soc 2010, 69:477-487.

34. UN: The Millennium Development Goals Report 2010. New York: United Nations; 2010.

35. Balshem $H$, Helfand M, Schunemann HJ, Oxman AD, Kunz R, Brozek J, Vist GE, Falck-Ytter Y, Meerpohl J, Norris S, Guyatt GH: GRADE guidelines: 3. Rating the quality of evidence. J Clin Epidemiol 2011, 64:401-406

36. Grazioso CF, Isalgue M, De Ramirez I, Ruz M, Solomons NW: The effect of zinc supplementation on parasitic reinfestation of Guatemalan schoolchildren. Am J Clin Nutr 1993, 57:673-678.

37. Saldiva SR, Carvalho HB, Castilho VP, Struchiner CJ, Massad E: Malnutrition and susceptibility to enteroparasites: reinfection rates after mass chemotherapy. Paediatr Perinat Epidemiol 2002, 16:166-171.

38. Long KZ, Estrada-Garcia T, Rosado JL, Ignacio Santos J, Haas M, Firestone M, Bhagwat J, Young C, DuPont HL, Hertzmark E, Nanthakumar NN: The effect of vitamin A supplementation on the intestinal immune response in Mexican children is modified by pathogen infections and diarrhea. J Nutr 2006, 136:1365-1370.

39. Long KZ, Rosado JL, Montoya Y, De Lourdes Solano M, Hertzmark E, DuPont $H L$, Santos Jl: Effect of vitamin A and zinc supplementation on gastrointestinal parasitic infections among Mexican children. Pediatrics 2007 120:e846-e855.

40. Payne LG, Koski KG, Ortega-Barria E, Scott ME: Benefit of vitamin A supplementation on Ascaris reinfection is less evident in stunted children. J Nutr 2007, 137:1455-1459.

41. Halpenny CM, Paller C, Koski KG, Valdés VE, Scott ME: Regional, household and individual factors that influence soil transmitted helminth reinfection dynamics in preschool children from rural indigenous Panamá. PLoS Negl Trop Dis 2013, 7:e2070.

42. Kightlinger LK, Seed JR, Kightlinger MB: Ascaris lumbricoides aggregation in relation to child growth status, delayed cutaneous hypersensitivity, and plant anthelmintic use in Madagascar. J Parasitol 1996, 82:25-33.

43. Olsen A, Nawiri J, Friis $\mathrm{H}$ : The impact of iron supplementation on reinfection with intestinal helminths and Schistosoma mansoni in western Kenya. Trans R Soc Trop Med Hyg 2000, 94:493-499.

44. Olsen A, Thiong'o FW, Ouma JH, Mwaniki D, Magnussen P, Michaelsen KF, Friis $H$, Geissler PW: Effects of multimicronutrient supplementation on helminth reinfection: a randomized, controlled trial in Kenyan schoolchildren. Trans R Soc Trop Med Hyg 2003, 97:109-114.

45. Nchito M, Geissler PW, Mubila L, Friis H, Olsen A: The effect of iron and multi-micronutrient supplementation on Ascaris lumbricoides reinfection among Zambian schoolchildren. Trans R Soc Trop Med Hyg 2009, 103:229-236.

46. Hesham Al-Mekhlafi M, Surin J, Atiya AS, Ariffin WA, Mohammed Mahdy AK, Che Abdullah H: Pattern and predictors of soil-transmitted helminth reinfection among aboriginal schoolchildren in rural Peninsular Malaysia. Acta Trop 2008, 107:200-204.

47. Nga T, Winichagoon P, Dijkhuizen MA, Khan NC, Wasantwisut E, Furr $H$, Wieringa FT: Multi-micronutrient-fortified biscuits decreased prevalence of anemia and improved micronutrient status and effectiveness of deworming in rural Vietnamese school children. J Nutr 2009, 139:1013-1021.

48. Nga T, Winichagoon P, Dijkhuizen MA, Khan NC, Wasantwisut $E_{1}$ Wieringa FT: Decreased parasite load and improved cognitive outcomes caused by deworming and consumption of multi-micronutrient fortified biscuits in rural Vietnamese schoolchildren. Am J Trop Med Hyg 2011, 85:333-340

49. Hagel I, Lynch NR, Di Prisco MC, Sanchez J, Perez M: Nutritional status and the $\mathrm{lgE}$ response against Ascaris lumbricoides in children from a tropical slum. Trans R Soc Trop Med Hyg 1995, 89:562-565.

50. Hagel I, Lynch NR, Di Prisco MC, Perez M, Sanchez JE, Pereyra BN, Soto de Sanabria I: Helminthic infection and anthropometric indicators in children from a tropical slum: Ascaris reinfection after anthelmintic treatment. J Trop Pediatr 1999, 45:215-220.

51. Tomkins A, Watson F: Malnutrition and Infection - A Review. Geneva: United Nations; 1989

52. Moher D, Liberati A, Tetzlaff J, Altman DG: Preferred reporting items for systematic reviews and meta-analyses: the PRISMA statement. PLoS Med 2009, 6:e1000097.

53. Jacobs DR Jr, Tapsell LC: Food, not nutrients, is the fundamental unit in nutrition. Nutr Rev 2007, 65:439-450.

54. Ahmann CF, Bristol LM: The effect of diet on the worm burden of children infected with Necator americanus and Ascaris lumbricoides. South Med J 1933, 16:959-962

55. Tripathy K, Garcia FT, Lotero H: Effect of nutritional repletion on human hookworm infection. Am J Trop Med Hyg 1971, 20:219-223.

56. Olsen A: Efficacy and safety of drug combinations in the treatment of schistosomiasis, soil-transmitted helminthiasis, lymphatic filariasis and onchocerciasis. Trans R Soc Trop Med Hyg 2007, 101:747-758.

57. Keiser J, Utzinger J: The drugs we have and the drugs we need against major helminth infections. Adv Parasitol 2010, 73:197-230.

58. Knopp S, Mohammed KA, Speich B, Hattendorf J, Khamis IS, Khamis AN, Stothard JR, Rollinson D, Marti H, Utzinger J: Albendazole and mebendazole administered alone or in combination with ivermectin 
against Trichuris trichiura: a randomized controlled trial. Clin Infect Dis 2010, 51:1420-1428.

59. Steinmann $P$, Utzinger J, Du ZW, Jiang JY, Chen JX, Hattendorf J, Zhou H, Zhou XN: Efficacy of single-dose and triple-dose albendazole and mebendazole against soil-transmitted helminths and Taenia spp.: a randomized controlled trial. PLoS One 2011, 6:e25003.

60. Yap P, Du ZW, Wu FW, Jiang JY, Chen R, Zhou XN, Hattendorf J, Utzinger J, Steinmann P: Rapid re-infection with soil-transmitted helminths after triple-dose albendazole treatment of school-aged children in Yunnan, People's Republic of China. Am J Trop Med Hyg 2013, 89:23-31.

doi:10.1186/1756-3305-7-229

Cite this article as: Yap et al:: Influence of nutrition on infection and re-infection with soil-transmitted helminths: a systematic review. Parasites \& Vectors 2014 7:229.

\section{Submit your next manuscript to BioMed Central and take full advantage of:}

- Convenient online submission

- Thorough peer review

- No space constraints or color figure charges

- Immediate publication on acceptance

- Inclusion in PubMed, CAS, Scopus and Google Scholar

- Research which is freely available for redistribution 